\title{
Heart Failure with Reduced Ejection Fraction—Does Sex Matter?
}

\author{
Sascha Swaraj ${ }^{1} \cdot$ Rebecca Kozor $^{1,2} \cdot$ Clare Arnott $^{3} \cdot$ Belinda A. Di Bartolo ${ }^{1} \cdot$ Gemma A. Figtree $^{1,2}$
}

Accepted: 27 August 2021 / Published online: 15 November 2021

(C) The Author(s) 2021

\begin{abstract}
Purpose of Review There is an increasing recognition of the importance of sex in susceptibility, clinical presentation, and outcomes for heart failure. This review focusses on heart failure with reduced ejection fraction (HFrEF), unravelling differences in biology, clinical and demographic features and evidence for diagnostic and therapeutic strategies. This is intended to inform clinicians and researchers regarding state-of-the-art evidence relevant to women, as well as areas of unmet need. Recent Findings Females are well recognised to be under-represented in clinical trials, but there have been some improvements in recent years. Data from the last 5 years reaffirms that women presenting with HFrEF women are older and have more comorbidities like hypertension, diabetes and obesity compared with men and are less likely to have ischaemic heart disease. Non-ischaemic aetiologies are more likely to be the cause of HFrEF in women, and women are more often symptomatic. Whilst mortality is less than in their male counterparts, HFrEF is associated with a bigger impact on quality of life in females. The implications of this for improved prevention, treatment and outcomes are discussed.

Summary This review reveals distinct sex differences in HFrEF pathophysiology, types of presentation, morbidity and mortality. In light of this, in order for future research and clinical medicine to be able to manage HFrEF adequately, there must be more representation of women in clinical trials as well as collaboration for the development of sex-specific management guidelines. Future research might also elucidate the biochemical foundation of the sex discrepancy in HFrEF.
\end{abstract}

Keywords Heart failure $\cdot$ Reduced ejection fraction $\cdot$ Sex $\cdot$ Gender $\cdot$ Male $\cdot$ Female

\section{Introduction}

Heart failure (HF) continues to increase in prevalence in our community in men and women, estimated to affect 64.34 million people globally [1]. The prevalence of HF appears significantly higher in the female sex globally (9.16 vs. 7.69 per million inhabitants) [1]. Women are more likely than

This article is part of the Topical Collection on Sex and Gender Aspects in Heart Failure

Gemma A. Figtree

gemma.figtree@sydney.edu.au

1 The Kolling Institute, University of Sydney, Sydney, NSW, Australia

2 Department of Cardiology, Royal North Shore Hospital, Sydney, Australia

3 The George Institute for Global Health, Imperial College London, London, UK males to have $\mathrm{HF}$ with preserved $\mathrm{EF}$ (HFpEF) and are about $65 \%$ less likely to develop HFrEF [2].

There has been a growing need, and widespread call, for increased representation of women in clinical trials, for studies to be powered for sex disaggregated analyses, and for guidelines to consider and reflect sex differences. Here, we review the most recent studies and literature and summarise the sex differences in demographics, mechanism, clinical presentation, biomarkers, outcomes, clinical pathways, management and representation in the literature for HFrEF.

In addition to referring to key early studies in the field, we systematically searched databases on Embase using the search strategy (HF with reduced ejection fraction OR HFrEF) and (gender or sex or female or male), limited to the English language, humans and the years 2016 to 2021. After removing duplicates, there were 488 results. After abstracts were screened, there were 42 studies and after reading the full texts, 33 were relevant to this review, with key themes summarized in (Fig. 1). 


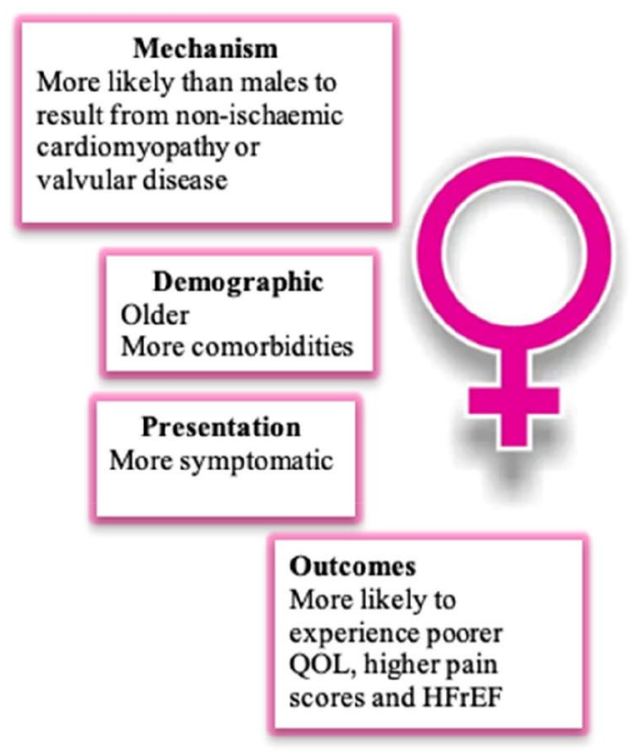

Fig. 1 Heart failure with reduced ejection fraction-does sex matter? The impact of sex in HFrEF can be demonstrated through the mechanisms and demographics, presenting features and outcomes. Where men are more likely to develop HFrEF from ischaemic heart disease (IHD), present with lower ejection fractions and have a higher mortality, women tend to have non-ischaemic cardiomyopathy or valvu-

\section{Clinical Demographic Differences}

\section{Age}

Whilst in both sexes the incidence of HF increases with age, it is well established that women are more likely to be older when presenting with HFrEF [3]. This is also reflected in more recent research over the last 5 years [4-6].

\section{Comorbidities}

In general, women with HFrEF have a higher prevalence of comorbidities than men. Women with HFrEF are more likely to have hypertension, diabetes, anaemia, thyroid disease and depression, and a greater burden of chronic kidney disease (CKD) [5-7]. They are less likely to have atrial fibrillation (AF) and ischaemic heart disease as underlying contributors compared to male HFrEF patients [2, 6]. In keeping with this, they are less likely to have had myocardial infarction, percutaneous coronary intervention and coronary artery bypass grafting [4]. Diabetes is an important risk factor in HF for both sexes, but to a greater degree in women [8]. Women with HFrEF are also less likely than men to smoke [9], have a lower level of education and are more likely to be unmarried, widowed or divorced [5].

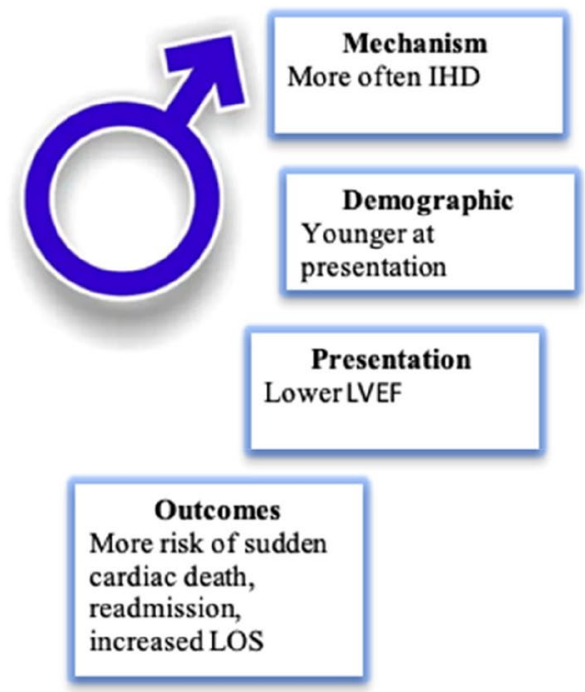

lar aetiology of HFrEF, be older at presentation, are more likely to have comorbidities like hypertension and chronic kidney disease, and experience more symptoms and report a poorer quality of life. QOL, quality of life; LOS, length of stay; HFrecEF, heart failure with recovered ejection fraction; IHD, ischaemic heart disease; LVEF, left ventricular ejection fraction

New data from the UK has found that women are more obese at presentation, and this obesity portends worse outcomes in women compared to men [5]. This may be largely due to obesity increasing the relative risk of coronary artery disease in women more than men (64\% vs $46 \%$, respectively) [2]. This however differed from a cohort of 5255 patients from an Asian registry [7] and 167 females from a Middle Eastern cohort where women with HFrEF had a lower BMI than men, with poorer outcomes, consistent with the so-called obesity paradox [10]. This data reflects the differing demographics and risk factors for women outside of western countries.

\section{Mechanisms}

There are key sex differences in the underlying mechanisms contributing to HFrEF, as well as differences in the susceptibility to each and the relative contribution to the burden of HFrEF.

\section{Ischaemic}

Whilst a driving precipitant of HFrEF in males is macrovascular coronary artery disease, myocardial ischaemia and infarction [11], HFrEF in women is more likely to be in association with older age, hypertension and valvular disease. Women with HFrEF are less prone than men to 
have macrovascular disease, including epicardial coronary artery disease or peripheral arterial disease, and stroke [3]. For example, the lifetime risk of HF in women with no history of myocardial infarction (MI) was 1 in 6, compared to 1 in 5 for all women. This likely indicates factors other than MI playing a relatively greater role in the development of HFrEF. In contrast, for men, the lifetime risk was approximately half as great in those free of MI (1 in 9) compared to all men ( 1 in 5), representing the heightened relevance of antecedent MI in men compared to women with HF [12].

\section{Non-Ischaemic}

There are some HF aetiologies that are unique to women, such as peripartum cardiomyopathy, with risk factors including advanced maternal age, and pre-eclampsia [13]. Additionally, the risk of cardiomyopathy from cardiotoxicity of breast cancer adjuvant chemotherapy can be as high as $42 \%$ indicating a need for long-term follow-up in these patients [14].

In patients with underlying myocardial dysfunction and cardiomyopathy, inflammation is increasingly recognised as playing a key role in a sex-specific manner. Sex discrepancies have recently been demonstrated in antibody-mediated immune response on cardiac remodelling in HFrEF, affecting progression of HF. We know that $\mathrm{IgG}$ can be found in the myocardium in patients with end-stage HFrEF associated with ischaemic heart disease (IHD). One study indicated that, in the early stages of remodelling, IgG1 and IgG3 levels differ between men and women [15]. Further research into implications of this is required to elucidate if inflammation in IHD confers a worse prognosis for remodelling, especially after an MI, whether this differs between sexes, and the implication for treatment.

Takotsubo cardiomyopathy is also more common in postmenopausal women. Whilst classically understood to be an acute and reversible condition, there is increasing appreciation of longer-term myocardial abnormalities and many patients continue to suffer symptoms which may be attributed to the recovery process $[16,17]$.

More evidence is emerging on the impact of sex hormones on sex discrepancy in HFrEF. There is increasing research on the protective effects of oestrogen on HF. Additionally, an oestrogen depletes postmenopausal state may contribute to women having higher left ventricular systolic and diastolic stiffness when compared to men as oestrogen is involved in blood pressure and arterial tone regulation [18]. Furthermore, the recent genetic variant analysis revealed the positive association between endogenous testosterone and HF [19, 20].

\section{Clinical Presentations}

In terms of presenting features of HFrEF, most recent data concurred with older data $[7,21]$ showing that women are more likely to experience symptoms like dyspnoea, exhibit a third heart sound (S3 gallop), increased jugular venous pressure, and leg oedema when compared to men. One paper conflicted with this but had a smaller sample size of 118 women and was restricted to a CCU setting [4]. It was reported that women experienced less symptoms with more normal ECGs.

Echocardiography analysis highlights that women have higher ejection fractions with smaller left atria, higher longitudinal strain and higher circumferential strain $[4,22]$. Asian women in particular more commonly have concentric left ventricular geometry compared to male counterparts [7]. Conversely, a large study looking at 12,058 men and 3357 women showed no difference in left ventricular ejection fraction between sexes [6]. Furthermore, whilst left ventricular (LV) systolic function is an important predictor of mortality in men, right ventricular function and $\mathrm{LV}$ diastolic function better predicted mortality in women [22]

As coronary microvascular and macrovascular dysfunction have similar risk factors, unique biological risk factor profiling is a promising method of early diagnosis [23]. Currently, this is quite limited, however, by discovering new mechanisms and exploring underlying aetiologies at a molecular level, more avenues may arise for future trial design to realise gender-specific guidelines. This could give rise to phenotyping of HF with sex differentiation. Recent data has been able to identify phenotypes of HFrEF via clustering variables like history of coronary artery bypass or percutaneous coronary intervention (PCI), sex, $\mathrm{CKD}$, race, etc., and show different mortality associated with each [24]. Further phenotyping with molecular level variables derived from omics analysis could elucidate sexbased differentiation of phenotypes as well.

\section{Biomarkers}

Biomarker identification in HF could identify potential targets for HF prevention in higher-risk individuals [25]. One biomarker already utilised is B-type natriuretic peptide (BNP), which has proven to be predictive of in-hospital mortality for both women and men in all types of HF [3]. Three studies explored serum biomarkers and their differences between the sexes. One showed similar levels of $\mathrm{N}$-terminal pro-BNP [6] between men and women, whilst another study showed women tended to have a higher BNP 
[26]. Although the implications are unknown currently, one paper discovered that high plasma concentrations of beta hydroxybuturate were associated with increased risk of HFrEF particularly in women [27].

Importantly, data from 12 years' worth of follow-up, after adjustment of risk factors, showed that a more androgenic hormone profile among post-menopausal women was associated with increased risk of HF [28]. Whilst exogenous hormone therapy in post-menopausal women is not beneficial for primary prevention, measuring endogenous hormone levels could be useful for risk stratification especially in populations known to have more androgenic profiles like in polycystic ovarian syndrome. In addition, there is evidence to also support the use of hsTroponin I alongside BNP in predicting new-onset HFpEF with similar reported effects in men and women $[29,30]$. Once risk of HFpEF is established, the same study also found that galectin-3 measurements could help monitor its progression over time. These, whilst promising, seem unlikely to be affected by sex or the presence of sex hormones highlighting the need for further evidence into varying biomarkers between HFrEF and $\mathrm{HFpEF}$ to aid in clinical diagnosis and management related to sex.

\section{Clinical Pathways}

International guidelines such as those of the European Society of Cardiology [31] or the American College of Cardiology [32] have provided clear pathways for initial investigations and subsequent treatment in patients presenting with $\mathrm{HFrEF}$ based on large-scale clinical trials. However, many of the clinical trials have a challenge with under-representation of females [33].

\section{Management}

\section{Medical Therapy}

Numerous recent studies have demonstrated that women are less likely to receive evidence-based medical therapy for treatment of HFrEF compared to their male colleagues [5, 6, 34]. Recent data from two large HFrEF trials (PARADIGM-HF and AT-MOSPHERE) has identified under prescribing of diuretics, anticoagulants and device therapy in women with HFrEF compared to men [6]. A major advance in the pharmacotherapy treatment for HFrEF has been the introduction of the angiotensin receptor-neurolysin inhibitor combination (ARNI). However, women have been observed to be less likely to receive appropriate prescription, with some studies showing female gender to be independently associated with lower odds of ARNI prescription
$[34,35]$. This data is even more striking in the context subgroup analysis from the PROVE-HF study showing that, when compared to men, women had a more rapid and early reduction in serum $\mathrm{N}$-terminal pro-BNP after ARNI initiation [36]. Furthermore, whilst women and men had similar degrees of reverse left ventricular remodelling after ARNI use, women displayed earlier and more consistent remodelling. The reports of lower rates of ARNI prescription, and lower diuretics, anticoagulants and device therapy contrast with reports of equal adherence to renin-angiotensin system inhibitors (ACEi), beta blockers, mineralcorticoid receptor antagonists and ivabradine, at least in the predominantly male study population of one study [5]. Additionally, a recent meta-analysis consisting of 13,833 patients, of which $24 \%$ were women, confirmed that, in patients with HFrEF in sinus rhythm, $\beta$-blockers reduced all-cause mortality and HF admissions, irrespective of age or sex [37].

Differences in tolerability and efficacy between drug therapies provide evidence that women require different guidelines for medical therapy of HFrEF $[11,38]$. For example, in women with HFrEF, the maximum drug benefit of a beta blocker is reached at $50-60 \%$ of the guideline-recommended dosing, decreasing the risk of all-cause death and HFrEF associated hospitalisation by $30 \%$ [11]. Similarly, for an ACEi, $40-60 \%$ of a standard dose is enough to reach efficacy in women, resulting in a $30 \%$ risk reduction. If women experience twice the rate of adverse events from HF drug regimes, as the literature suggests [11], there is a clear impetus for sex-based dosing targets and guidelines. Additionally, with digoxin use, plasma concentrations in women were higher than men at guideline dosing, increasing the risk of digoxin-related mortality. Women in their patient population were older with lower body weight and height [35], and these sex differences can effect pharmacokinetics and pharmacodynamics. Guidelines that inform drug dosing are often reliant on research with limited female participation [39]. Further clinical research is needed to confirm the presence of differential dose efficacy between sexes and then define sex-specific, and even age-specific optimal dosing.

\section{Device Therapy}

Advances in electric and mechanical devices have continued with substantial benefits for patient symptoms, hospitalisation and outcomes, with strong evidence in both sexes [40] (Table 1). The range of devices includes implantable cardioverter defibrillators (ICD), cardiac resynchronisation therapy (CRT) and cardiac resynchronisation therapy defibrillators. However, recent data shows women are less likely to receive an ICD, and when they do, they have higher rates of implantation-related complications like pneumothorax and infection [11]. 
Table 1 Guideline-based therapy application in females with HFrEF
Specific differences in Likelihood of getting evidence-based

benefits between sexes treatment

Dose adjustment required

BNP B-type natriuretic peptide, TTE transthoracic echocardiogram, ACEI angiotensin-converting enzyme inhibitors, $A R B$ angiotensin II receptor blockers, $A R N I$ angiotensin receptor neprilysin inhibitor, ICD implantable cardioverter-defibrillator, $C R T$ cardiac resynchronization therapy, $H F r E F$ heart failure reduced ejection fraction.

\section{Cardiac Rehabilitation and Lifestyle Modifications}

There is strong evidence, reflected in the guidelines, for cardiac rehabilitation (including education), and lifestyle modifications including salt reduction, weight loss, and exercise (strong evidence) and a whole grain plant-based diet (less evidence) [41], in improving quality of life and outcomes in patients with HFrEF [42]. Disappointingly, women are seen to have lower enrolment and completion of cardiac rehabilitation, and this may be due to sex-specific discrepancies in presenting factors like being older, with more comorbidities and less social supports [11]. Ultimately, the female gender is associated with being less likely to receive optimal treatment as recommended by guidelines [43].

\section{Outcomes}

The literature reports on multiple outcomes in HF, exploring mortality, quality of life, rates of hospitalisation and readmission, susceptibility to arrhythmia, and recovery of LV function. The previous body of evidence found no difference in-hospital mortality between sexes, which also correlated with several recent studies $[4,44]$. A few recent studies reported a lower rate of mortality in women [6, 45], with one also reporting that sudden cardiac death occurred more often in males with HFrEF [46]. A recent prospective multicentre cohort study showed that women with ischaemic heart disease and HFrEF had a lower survival rate than women without IHD $(p=0.001)$, and this survival difference was not observed in men [47].

Previous literature had described that females with HF report lower quality of life, and this was reiterated in new data [6]. Despite females living longer than their male counterparts with HFrEF, they experienced more symptoms and signs, ultimately had a poorer quality of life, higher pain scores and greater self-reported psychological and physical disability [48]. Similarly, when Kansas City Cardiomyopathy Questionnaire (KCCQ) scores of patients with HFrEF were compared, female patients scored 1.8 points lower than males [49]. In terms of another morbidity, new data from a study that surveyed patients after PCI showed that, at 30 days follow-up, rates of arrhythmia and recurrent MI were higher in women with HFrEF compared to men [24].

Regarding rates of hospitalisations, most data, including more recent studies, showed that women have a lower risk of hospitalisation [6]. Only one recent paper showed women had more hospitalisations than men, albeit reporting on a mostly male population (70.1\%) [5]. Additionally, papers reviewed in the last 5 years also indicated women were less likely to be readmitted for HF and had a shorter length of stay $[4,50,51]$.

Although many studies have explored predictive factors for HF with recovered ejection fraction, few have sought to understand whether there is a gender discrepancy. More recent data has identified a link between female sex and left ventricular ejection fraction recovery [52-54]. One retrospective cohort study elucidated specific clinical phenotypes 
and predictors for ejection fraction recovery and showed that females were more likely to recover $(10.1 \%$ vs $14 \%$, $p=0.04$ ) [48]. Since patients with recovered ejection fraction have a much better prognosis compared to those with HFrEF, female patients in these studies also exhibited a lower mortality risk compared to men. Regarding complications, whilst diabetes confers a worse quality of life in patients with HFrEF irrespective of sex, there is a greater risk of adverse outcomes in women than men with diabetes [8].

An important consideration in the interpretation of the literature in regard to heart failure outcomes is the often-poor stratification of analyses and reports by acute versus ambulant or chronic heart failure, with less data available regarding sex differences in the acute heart failure setting. Data that is available suggests that, whilst co-morbidities at the time of presentation differ between the sexes, acute in-hospital outcomes are similar. For example, in the ALARM-HF multinational survey of over 4000 patient hospitalizations, men were more likely to have acute coronary syndrome as the precipitating event and underlying coronary artery disease, and women were more likely to have concomitant AF, obesity, anaemia and depression. In hospital, mortality, however, was similar in both sexes (11\%) [55]. This contrasts with the lower mortality risk more broadly observed in women with heart failure discussed above.

\section{Sex Representation in Literature}

Four studies closely analysed and quantified female representation in trials. Female participation in landmark HF trials ranged from 0 to $40 \%$ with an average of $20 \%$ [26]. In an analysis of $118 \mathrm{HF}$ trials, 58,873 of 215,508 people enrolled were women ( $27 \%$ on average), improving from $26 \%$ in 2001-2004 to $29 \%$ in 2013-2016 [33]. Another study found that females represented only $25.5 \%$ of enrolled participants with HFrEF (ranging from 4 to $68 \%$ in each trial) when looking at 317 randomised control trials. Another explanation for poor female representation relative to how many females are affected by HF may be due to 81 of those studies using sex-specific exclusion criteria (e.g., childbearing, menopausal status) without explanation. As a result, among these 81 studies, only $23.3 \%$ of the sample population was female [56].

Under representation of females in clinical trials and lack of sex-disaggregated data means studies are often underpowered to apply results to clinical practice. For more than 25 years, there has been an acknowledgement of the sex discrepancy in HFrEF [57], and despite this, the underrepresentation of women in clinical trial data continues. The lack of sex disaggregation perpetuates the inability for sexspecific treatment and diagnostic guidelines.

\section{Conclusion}

The sex differences in HF with reduced ejection fraction are undeniable. The pathophysiology, types of presentation, morbidity and mortality differ between the sexes. However, without more representation of women in clinical trials, the development of sex-specific management guidelines appears improbable.

\section{Declarations}

Conflict of Interest The authors declare no competing interests.

Human and Animal Rights and Informed Consent This article does not contain any studies with human or animal subjects performed by any of the authors.

Open Access This article is licensed under a Creative Commons Attribution 4.0 International License, which permits use, sharing, adaptation, distribution and reproduction in any medium or format, as long as you give appropriate credit to the original author(s) and the source, provide a link to the Creative Commons licence, and indicate if changes were made. The images or other third party material in this article are included in the article's Creative Commons licence, unless indicated otherwise in a credit line to the material. If material is not included in the article's Creative Commons licence and your intended use is not permitted by statutory regulation or exceeds the permitted use, you will need to obtain permission directly from the copyright holder. To view a copy of this licence, visit http://creativecommons.org/licenses/by/4.0/.

\section{References}

1. Lippi G, Sanchis-Gomar F. Global epidemiology and future trends of heart failure. AME Med J 2020;5.

2. Kenchaiah S, Vasan R. Heart failure in women - insights from the Framingham Heart Study. Cardiovasc Drugs Ther. 2015;29:37790. https://doi.org/10.1007/s10557-015-6599-0.

3. Hsich EM, Grau-Sepulveda M, Hernandez AF, Eapen ZJ, Xian Y, Schwamm LH, et al. Relationship between sex, ejection fraction, and B-type natriuretic peptide levels in patients hospitalized with heart failure and associations with inhospital outcomes: findings from the Get With The Guideline-Heart Failure Registry. Am Heart J. 2013;166(6):1063-71. https://doi.org/10.1016/j.ahj. 2013.08.029.

4. Badran HM, Elgharably M, Faheem N. Clinical characteristics and in-hospital outcomes of heart failure in women: a single center registry from Egyptian cardiac care unit. . Egypt Heart J. 2019;71(1):doi.org/https://doi.org/10.1186/s43044-019-0032-0.

5. Kocabas U, Kivrak T, Oztekin GMY, Tanik VO, Ozdemir I, Kaya $\mathrm{E}$, et al. Gender related clinical and management differences in patients with chronic heart failure with reduced ejection fraction. . Int J Clin Pract. 2020;75(3):doi.org/https://doi.org/10.1111/ijcp. 13765. .

6. Dewan P, Rorth R, Jhund PS, Shen L, Raparelli V, Petrie MC, et al. Differential impact of heart failure with reduced ejection fraction on men and women. J Am Coll Cardiol. 2019;73(1):2940. https://doi.org/10.1016/j.jacc.2018.09.081. 
7. Chandramouli C, Teng TK, Tay WT, Yap J, MacDonald MR, Tromp J, et al. Impact of diabetes and sex in heart failure with reduced ejection fraction patients from the ASIA-HF registry. Eur J Heart Fail. 2019;21(1):297-307. https://doi.org/10.1002/ ejhf.358.

8. Kannel WB, Hjortland M, Castellin WP. Role of diabetes in congestive heart failure: the Framingham study. Am J Cardiol. 1974;34(1):29-34. https://doi.org/10.1016/0002-9149(74) 90089-7.

9. Frazier CG, Alexander K, Newby LK, Anderson S, Iverson E, Packer M, et al. Associations of gender and etiology with outcomes in heart failure with systolic dysfunction: a pooled analysis of 5 randomized control trials. J Am Coll Cardiol. 2007;49(13):1450-8. https://doi.org/10.1016/j.jacc.2006.11.041.

10. Khaled S, Matahen R. Obesity paradox in heart failure patientsfemale gender characterisitcs-KAMC -single centre experience Egypt Heart J. 2017;69(3):209-13. https://doi.org/10.1016/j.ehj. 2017.06.002.

11. Lam CSP, Arnott C, Beale AL, Chandramouli C, Hilfiker-Kleiner, Kay DM et al. Sex differences in heart failure. . Eur Heart J 2019;40(47):3859-68c.doi: https://doi.org/10.1093/eurheartj/ ehz835.

12. Lloyd-Jones DM, Larson M, Leip EP, Beiser A, D'Agostino $\mathrm{RB}$, Kannel WB, et al. Lifetime risk for developing congestive heart failure. The Framingham Heart Study Circulation. 2002;106(24):3068-72. https://doi.org/10.1161/01.cir.00000 39105.49749.6f.

13. Arany Z, Elkayam U. Peripartum cardiomyopathy. Circulation. 2016;133(14):1397-409. https://doi.org/10.1161/CIRCULATIO NAHA.115.020491.

14. Chen J, Long J, Hurria A, Owusu C, Steingart RM, Gross CP. Incidence of heart failure or cardiomyopathy after adjuvant trastuzumab therapy for breast cancer. J Am Coll Cardiol. 2012;60(24):2504-12. https://doi.org/10.1016/j.jacc.2012.07.068.

15. Hoogen $P$, Jager S, Huibers MMH, Schoneveld AH, Puspitasari YM, Valstar GB, et al. Increased circulating IgG levels, myocardial immune cells and IgG deposits support a role for an immune response in pre- and end-stage heart failure. J Cell Mol Med. 2019;23(11):7505-16. https://doi.org/10.1111/jcmm.14619.

16. Murakami T, Yoshikawa T, Maekawa Y, Ueda T, Isogai T, Sakata $\mathrm{K}$, et al. Gender differences in patients with Takotsubo cardiomyopathy: multi-center registry from Tokyo CCU network. PLoS ONE. 2015;10(8): e0136655. https://doi.org/10.1371/journal. pone.

17. Lyon AR, Bossone E, Schneider B, Sechtem U, Citro R, Underwood SR, et al. Current state of knowledge on Takotsubo syndrome: a position statement from the Taskforce on Takotsubo Syndrome of the Heart Failure Association of the European Society of Cardiology. Eur J Heart Fail. 2016;18(1):8-27. https://doi. org/10.1002/ejhf.424.

18. Sullivan K, Doumouras BS, Santema BT, Walsh MN, Douglas PS, Voors AA, et al. Sex-specific differences in heart failure: pathophysiology, risk factors, management, and outcomes. Can J Cardiol. 2021;37(4):560-71.

19. Iorga A, Cunningham CM, Moazeni S, Ruffenach G, Umar S, Eghbali M. The protective role of estrogen and estrogen receptors in cardiovascular disease and the controversial use of estrogen therapy. Biol Sex Differ. 2017;8(1):33-.

20. Luo S, Au Yeung SL, Zhao JV, Burgess S, Schooling CM. Association of genetically predicted testosterone with thromboembolism, heart failure, and myocardial infarction: mendelian randomisation study in UK Biobank. BMJ (Clinical research ed) [Internet]. 2019 2019/03//; 364:[1476 p.]. Available from: http://europepmc.org/ abstract/MED/30842065, https://doi.org/10.1136/bmj.1476

21. Johnstone D, Limacher M, Rousseau M, Liang CS, Ekelund $\mathrm{L}$, Herman M, et al. Clinical characteristics of patients in studies of left ventricular dysfunction (SOLVD). Am J Cardiol. 1992;70(9):894-900. https://doi.org/10.1016/0002-9149(92) 90734-g.

22. Lundorff IJ, Sengelov M, Jorgensen PG, Pedersen S, Modin D, Bruun NE, et al. Echocardiographic predictors of mortality in women with heart failure with reduced ejection fraction. Circ Cardiovasc Imaging. 2018;11(11): e008031. https://doi.org/10.1161/ CIRCIMAGING.118.

23. Swaraj S, Kott K, Vernon S, Figtree G. Microvascular dysfunction: assessment of risk factors in patients with positive stress tests but no obstructive epicardial coronary artery disease. Heart Lung Circ 2020;29:doi.org/https://doi.org/10.1016/j.hlc.2020.09.745

24. Doran B, Roeder C, Merrill M, Jhund P, Stevens L, McMurray J et al. Latent cluster analysis using clinical and functional characteristics identifies novel phenotypes of patients with reduced ejection fraction enrolled in the HF-ACTION trial with differential association with mortality. Circulation. 2018;138:doi/abs/https:// doi.org/10.1161/circ.138.suppl_1.12890.

25. Ledwidge M, Gallagher J, Conlon C, Tallon E, O'Connell E, Dawkins I, et al. Natriuretic peptide-based screening and collaborative care for heart failure: the STOP-HF randomized trial. JAMA. 2013;310(1):66-74. https://doi.org/10.1001/jama.2013. 7588.

26. Mentzer G, Hsich E. Heart failure with reduced ejection fraction in women: epidemiology, outcomes, and treatment. Heart Fail Clin. 2018;15(1):19-27. https://doi.org/10.1016/j.hfc.2018.08. 003.

27. Flores-Guerrero JL, Westenbrink B, Connelly MA, Otvos JD, Groothof D, Shalaurova I, et al. Association of beta-hydroxybutyrate with development of heart failure: sex differences in a Dutch population cohort. Eur J Clin Invest. 2020;1-11:13468. https://doi.org/10.1111/eci.

28. Zhao D, Guallar E, Ouyang P, Subramanya V, Vaidya D, Ndumele $\mathrm{CE}$, et al. Sex hormones, CVD and heart failure in women. J Am Coll Cardiol. 2018;71(33):2555-66. https://doi.org/10.1016/j.jacc. 2018.01.083.

29. Watson CJ. Biomarker profiling for risk of future heart failure (HFpEF) development. Journal of Translational Medicine. $2021 ; 19$.

30. Suthahar N, Meems LMG, Ho JE, de Boer RA. Sex-related differences in contemporary biomarkers for heart failure: a review. Eur J Heart Fail. 2020;22(5):775-88. https://doi.org/10.1002/ejhf. 771.

31. Ponikowski P, Voors AA, Anker SD, Bueno H, Cleland JGF, Coats AJS, et al. 2016 ESC Guidelines for the diagnosis and treatment of acute and chronic heart failure: The Task Force for the diagnosis and treatment of acute and chronic heart failure of the European Society of Cardiology (ESC)Developed with the special contribution of the Heart Failure Association (HFA) of the ESC. Eur Heart J. 2016;37(27):2129-200.

32. Yancy CW, Jessup M, Bozkurt B, Butler J, Casey DE, Colvin M, et al. 2017 ACC/AHA/HFSA Focused Update of the 2013 ACCF/ AHA Guideline for the management of heart failure: a report of the American College of Cardiology/American Heart Association Task Force on Clinical Practice Guidelines and the Heart Failure Society of America Clinical Practice Guideline: Focused Update. J Am Coll Cardiol. 2017;70(6):776-803.

33. Tahhan AS, Vaduganathan M, Greene SJ, Fonarow GC, Fiuzat M, Jessup M, et al. Enrollment of older patients, women, and racial and ethnic minorities in contemporary heart failure clinical trials a systematic review. JAMA Cardiol. 2018;3(10):1011-9. https:// doi.org/10.1001/jamacardio.2018.559.

34. Loefroth E, Shen X, Studer R, Schlienger R, Proudfoot C, Stefano C. et al. Comparison of heart failure patients newly prescribed sacubitril/valsartan with those newly prescribed aceis/arbs; a 
cohort study using US optum electronic health record data. Circulation. 2020;142.

35. Eberly L, Yang L, Geng Z, Nathan A, Khatana SM, Dayoub E. et al. Racial, gender, and socioeconomic differences in sacubitrilvalsartan and ivrabridine utilisation for the management of heart failure with reduced ejection fraction in the United States. Circulation 2020;13.

36. Ibrahim NE, Pina I, Camacho A, Bapat D, Felker MG, Maisel AS. et al. Sex-based differences in biomarkers, health status, and reverse cardiac remodelling in patients with heart failure with reduced ejection fraction treated with sacubitril/valsartan.Eur J Heart Fail 2020;22:2018-25. doi:https://doi.org/10.1002/ejhf. 2005.

37. Kotecha D, Manzano L, Krum H, Rosano G, Holmes J, Altman DG. et al. Effect of age and sex on efficacy and tolerability of $b$ blockers in patients with heart failure with reduced ejection fraction: individual patient data meta analysis. BMJ. 2016;353.

38. Santema BT, Ouwerkerk W, Tromp J, Sama IE, Ravera A, RegitzZagrosek V, et al. Identifying optimal dosing of heart failure medications in men compared with women: a prospective, observational, cohort study. The Lancet. 2019;394(10205):1254-63. https://doi.org/10.1016/S0140-6736(19)31792-1.

39. DeFilippis EM, Van Spall HGC. Is it Time for Sex-Specific Guidelines for Cardiovascular Disease? J Am Coll Cardiol. 2021;78(2):189-92.

40. A. M. Overview of devices in advanced heart failure. eJournal of Cardiology practice. 2017;14(41).

41. Aggarwal M, Bozkurt B, Panjrath G, Aggarwal B, Ostfeld RJ, Barnard ND, et al. Lifestyle modifications for preventing and treating heart failure. J Am Coll Cardiol. 2018;72(19):2391-405. https://doi.org/10.1016/j.jacc.2018.08.160.

42. Atherton JJ, Sindone A, De Pasquale CG, Driscoll A, MacDonald PS, Hopper I, et al. National Heart Foundation of Australia and Cardiac Society of Australia and New Zealand: Australian clinical guidelines for the management of heart failure 2018. Heart Lung Circ. 2018;27(10):1123-208. https://doi.org/10.1016/j.hlc.2018. 06.1042 .

43. Chin K, Skiba M, Tonkin A, Reid C, Liew D, Krum H. et al. Treatment gap in heart failure with reduced ejection fraction patients: how well are we implementing evidence-based care? Heart Lung Circ. 2016;25.

44. Dagan M, Dinh D, Stehli J, Tan C, Brennan A, Warren J et al. Impact of sex on heart failure pharmacotherapy and outcomes in patients with ischaemic heart disease and comorbid heart failure with reduced ejection fraction. Heart Lung Circ. 2020;29:doi. org/https://doi.org/10.1016/j.hlc.2020.09.130.

45. Vafaei P, Leong T, Sung SH, Lee KK and Go AS. Contemporary evaluation of female gender and outcomes in heart failure with reduced or preserved left ventricular systolic function. Circulation. 2016;134:doi/https://doi.org/10.1161/circ.134.suppl_1. 12921.

46. Shen L, Jhund P, Petrie MC, Claggett BL, Barlera S, Cleland JFG, et al. Declining risk of sudden death in heart failure. N Engl $\mathrm{J}$
Med. 2017;377(1):41-51. https://doi.org/10.1056/NEJMoa1609 758.

47. Kim H, Kim M, Kim H, Choi D, Han S, Jeon E, et al. Gender differences in the impact of ischaemic heart disease on heart failure. Eur J Clin Invest. 2020;50(5): e13232. https://doi.org/10.1111/eci.

48. Feng KY, Oconnor C, Clare R, Alhanti B, Pina IL, Kraus WE et al. Exploring the implications of pain symptoms in patient with heart failure. Circulation 2019;140.

49. Khariton Y, Nassif M, Thomas L, Fonarow GC, Mi X, DeVore A et al. Gender and socioeconomic disparities with health status in outpatients with heart failure: insights from the CHAMP-HF Registry. Circulation. 2018;136:Abstract 19403. doi/https://doi. org/10.1161/circ.136.suppl_1.

50. Millhouse J, Memon S. Predictors of increased length of stay in heart failure: an Australian Tertiary Hospital Experience. Heart Lung Circ 2020;29:DOI:https://doi.org/10.1016/j.hlc.2020.09. 157.

51. Cleveland ER, Berkowitz C, Pissaris A, Valencia V, Mutharasan RK. Gender equity in rates of guideline directed medical therapy prescription at discharge for hospitalised heart failure patients. . Circulation. 2019;11:doi/https://doi.org/10.1161/circoutcomes.11. suppl_1.251.

52. Olsen C, Mandawat A, Triana T, Samsky MD, Chiswell K, Karra $\mathrm{R}$. Recovery of left ventricular function on LVAD support is associated with improved outcomes. Circulation 2020;142.

53. Yaranov D, Patel P, Ostwani W, Esmail K, Tinsley J, Miller AB. Ethnicity and gender predict ejection fraction recovery in patients with heart failure and reduced ejection fraction in a large urban teaching medical center. Circulation 2017;136.

54. Ghimire A, Fine N, Ezekowitz JA, Howlett J, Youngson E, McAlister FA. Frequency, Predictors, and prognosis of ejection fraction improvement in heart failure: an echocardiogram-based registry study. Eur Heart J. 2019;40:2110-7. https://doi.org/10.1093/eurhe artj/ehz233.

55. Parissis JT, Mantziari L, Kaldoglou N, Ikonomidis I, Nikolaou M, Mebazaa A, et al. Gender-related differences in patients with acute heart failure: management and predictors of in-hospital mortality. Int J Cardiol. 2013;168(1):185-9.

56. Whitelaw S, Sullivan K, Eliya Y, Alruwayeh M, Thabane L, Yancy $\mathrm{CW}$, et al. Trial characteristics associated with under-enrolment of females in randomized controlled trials of heart failure with reduced ejection fraction: a systematic review. Eur J Heart Fail. 2021;23(1):15-24. https://doi.org/10.1002/ejhf.2034.

57. Johnson MR. Heart failure in women: a special approach? J Heart Lung Transplant. 1994;13(4).

Publisher's Note Springer Nature remains neutral with regard to jurisdictional claims in published maps and institutional affiliations. 